\title{
Medicalização e normalização da sociedade
}

\author{
Medicalization and normalization of society
}

Medicalización y normalización de la sociedade

\author{
Flavia Cristina Silveira Lemos \\ Geise do Socorro Lima Gomes \\ Paulo de Tarso Ribeiro de Oliveira \\ Universidade Federal do Pará (UFPA), Belém, PA, Brasil \\ Dolores Cristina Gomes Galindo \\ Universidade Federal do Mato Grosso (UFMT), Cuiabá, MT, Brasil
}

\begin{abstract}
Resumo
Este artigo é um ensaio temático e teórico sobre as práticas de medicalização, a partir das análises de Michel Foucault sobre poderes e saberes da disciplina e da biopolítica, em um campo da bio-história e da normalização da sociedade. O texto apresenta alguns aspectos que sustentam processos de medicalização por meio da racionalidade patologizadora dos corpos e das relações sociais, culturais e subjetivas. A docilização da existência e a gerência da vida passaram a fazer parte dos cálculos no biopoder, se tornando dispositivos de governo das condutas, na sociedade contemporânea. Governar a vida em nome da expansão da mesma e do aumento da saúde implica um ato permanente de organizar os corpos e a saúde deles, de acordo com os critérios do Estado sobre saúde.
\end{abstract}

Palavras-chave: Medicalização; Biopoder; Norma; Sociedade; Governo.

\begin{abstract}
This article is a thematic and theoretical essay on the practices of medicalization, based on Michel Foucault's analysis of the powers and knowledges of discipline and biopolitics, in a field of bio-history and the normalization of society. The text presents some aspects that support processes of medicalization through the pathological rationality of bodies and social, cultural and subjective relations. The docilization of existence and the management of life became part of the calculations in biopower, becoming devices of governance of the conduct in contemporary society. Governing life in the name of expanding it and increasing health implies a permanent act of organizing their bodies and their health, according to the state's health points.
\end{abstract}

Keywords: Medicalization; Biopower; Standard; Society; Government. 


\section{Resumen}

Este artículo es un ensayo temático y teórico sobre prácticas de medicalización, basado en el análisis de Michel Foucault de los poderes y el conocimiento de la disciplina y la biopolítica, en un campo de la biohistoria y la normalización de la sociedad. El texto presenta algunos aspectos que apoyan los procesos de medicalización a través de la racionalidad patologizante de los cuerpos y las relaciones sociales, culturales y subjetivas. La docilización de la existencia y el manejo de la vida se convirtieron en parte de los cálculos en biopoder, convirtiéndose en dispositivos para conducir conductas en la sociedad contemporánea. Gobernar la vida en nombre de expandirla y aumentar la salud implica un acto permanente de organizar sus cuerpos y su salud, de acuerdo con los criterios de salud del Estado.

Palabras-clave: Medicalización; Biopoder; Estándar; Sociedad; Gobierno.

\section{Introdução}

Este artigo tem o objetivo de problematizar as práticas medicalizantes, a partir da normalização da sociedade. Busca-se analisar como as normas são acionadas para operar processos de medicalização social por meio da anatomopolítica e da biopolítica, considerando os aportes de Michel Foucault no campo da Filosofia e da História.

\section{Anatomopolítica, bio-história e medicalização}

A história do corpo humano se confunde com a das intervenções sobre o mesmo. A esse respeito Foucault (2011d) vai chamar de bio-história, a história do homem e da vida e suas implicações. Dentro dessa bio-história, situa o desenvolvimento de tecnologias de poder que, por volta do século XVII, vão objetivar o corpo a partir de uma preocupação com a vida, no sentido de buscar recursos, estratégias, técnicas que garantam o prolongamento desta. Ao conjunto que se cria com esses propósitos, o autor vai designar de biopoder. Este conceito por sua vez, abarca dois diferentes modos de investimentos políticos do poder sobre a vida: em nível individual e coletivo. Às intervenções individuais Foucault (2005a) vai chamar de anatomopolíticas e às intervenções coletivas de biopolítica. As duas formas se atravessam, mas na análise mais pormenorizada, percebemos que estão imanentes em suas funções particularizadas. Rabinow e Rose (2006, p. 28) explicam essas especificações realizadas pelo filósofo:

\footnotetext{
O conceito de biopoder serve para trazer à tona um campo composto por tentativas mais ou menos racionalizadas de intervir
} 
sobre as características vitais da existência humana. As características vitais dos seres humanos, seres viventes que nascem, crescem, habitam um corpo que pode ser treinado e aumentado e, por fim adoecem e morrem. E as características vitais das coletividades ou populações compostas de tais seres viventes. E, enquanto Foucault é de algum modo impreciso em seu uso dos termos no campo do biopoder, podemos usar o termo "biopolítica" para abarcar todas as estratégias específicas e contestações sobre as problematizações da vitalidade humana coletiva, morbidade e mortalidade, sobre as formas de conhecimento, regimes de autoridade e práticas de intervenção que são desejáveis, legítimas e eficazes.

Esses autores chamam a atenção para as condições em que esses conceitos foram sendo forjados por Foucault, uma vez que nasceram baseados em estudos históricos, específicos, não caracterizando conceitos "trans-históricos", mas que pontuavam determinadas práticas e acontecimentos. Assim, para o domínio da anatomopolítica, Foucault (2008d) estudou e descreveu as estratégias e os mecanismos empregados para obter maior eficiência dos corpos individuais, garantindo ao mesmo tempo a docilidade do sujeito.

Os mecanismos disciplinares são confeccionados, espalhados em diversas esferas da sociedade, por meio do exame, da sanção normalizadora e da vigilância. Já na biopolítica, os artefatos foram direcionados para a regulamentação da população por meio do controle das taxas de morbidade e mortalidade, no uso de estatísticas e cálculos probabilísticos sobre os supostos riscos que a população padeceria. Essa bipolaridade do poder, por sua vez ancorava-se ou era proveniente de saberes diversos: a epidemiologia, a psicologia, a estatística, o direito, a medicina, a pedagogia, a economia e outros (Foucault, 2008i). Um desses saberes corresponde ao campo da medicina, que teve maior notoriedade a partir do século XVIII, com o aperfeiçoamento de instrumentos para explorar com mais exatidão o corpo humano (Ortega \& Zorzanelli, 2010).

Foucault (2011a, 2011b) vai afirmar que essa intervenção médica a nível biológico vai deixar na humanidade um rastro de medicalização, ou seja, sob a tutela dos saberes médicos e saberes biológicos, uma diversidade de discursos sobre higiene, condutas, saúde, comportamentos são produzidos e integram uma rede capilar de medicalização, interferindo por sua vez na construção de instituições, sistemas de limpeza, transporte, conservação, etc., até que nada escape às suas teias.

Foucault (2011a) situa quatro grandes processos que vão caracterizar a 
medicina do século XVIII: 1) o aparecimento de uma autoridade médica; 2) o surgimento de um campo de intervenção da medicina distinto da doença; 3) introdução de um aparelho de medicalização coletiva: o hospital; 4) introdução de mecanismos de administração médica. No primeiro caso, teremos um saber que expande sua "área de conhecimento" tornando-se uma autoridade social a decidir questões relativas a uma cidade, a um bairro, criação de instituições e regulamentos. É uma prática da medicina vinculada ao Estado, exemplificada pelo pensador, com o exemplo do que ocorreu na Alemanha: "A criação de funcionários médicos nomeados pelo governo com responsabilidade sobre uma região, seu domínio de poder ou de exercício da autoridade de seu saber" (Foucault, 2008a, p. 84).

$\mathrm{Na}$ segunda característica vão se tornar objetos da medicina o ar, a água, os esgotos, as construções. Intervenções na regulação das cidades e de seu funcionamento, que tem essas características, maior dimensionadas na França, como uma medicina urbana ou medicina das coisas, como afirma Foucault (2011a). O hospital, como terceiro elemento, sendo um sistema de confinamento coletivo vai se tornar uma instituição de medicalização a partir do século XVIII. Antes disso, era um lugar com fins assistenciais para pobres, um lugar para morrer, um mecanismo de exclusão, de conversão espiritual, menos médico. Foucault (2011c) evidencia que o hospital ganha uma função terapêutica a partir de uma nova prática que consistia na comparação entre os hospitais por meio de visitas e observações sistemáticas. No texto "A incorporação do hospital na tecnologia moderna" (2011c) vai falar mais detalhadamente desse processo, exemplificando como que esta instituição vai mudar de função a partir da introdução de mecanismos disciplinares no espaço desordenado do hospital. E por fim, na criação de mecanismos de administração médica, Foucault (2011b) vai dar como exemplos, registros de dados, comparações estatísticas, que vão compor e endossar o campo da medicalização. Todos esses elementos fazem a medicina, considerada uma prática individual, alcançar um alastramento totalmente novo, configurando-se agora como uma prática social. Há, para Foucault nesse momento, um desbloqueio epistemológico da medicina, em que se abrem,

\footnotetext{
[...] as possibilidades da anatomia patológica, da grande medicina hospitalar e dos progressos simbolizados pelos nomes de Bichat, Laennec, Bayle etc. Por conseguinte, a medicina se dedica a outros
} 
domínios diferentes dos da doença e que não são regidos pela demanda do paciente. Esse é um velho fenômeno que faz parte das características fundamentais da medicina moderna (Foucault, 2011b, p. 385).

Esse acontecimento vai ser definido por Foucault como "medicalização indefinida" uma vez que seu direcionamento ao longo dos séculos até a atualidade foi se espraiando para diversos espaços, embora, ressalte Foucault (2011b) que no século $\mathrm{XX}$ tentou-se delimitar mais o "campo da medicina", a partir do doente, da sua dor, dos seus sintomas, do seu malestar, circunscrevendo um conjunto de objetos considerados "doentes". Essa "limitação" encontrou fissuras para escape por meio das práticas autoritárias da medicina, que exerce sobre o doente uma função de autoridade.

Nos cita como exemplo, os casos de contratação que exigem parecer médico; as políticas sistemáticas e obrigatórias de screening, de localização da doença no conjunto da população e que não surgiram de demandas de doentes; em alguns casos de julgamento judiciários, em muitos países solicita-se avaliações psiquiátricas. Outro exemplo, sobre intervenção médica em objetos que não são da competência médica, Foucault cita o comportamento sexual ou a sexualidade. A esse respeito, tudo que se considera como desvio ou anomalias é capturado pela intervenção médica, mesmo, como ressalta o autor, sem nunca alguém ter dito que anomalia sexual é uma doença. Trata-se, portanto, de observarmos que tudo que se diz referente à saúde, acabou se tornando objeto de intervenção médica. Assim, se o ar está contaminado ou não, se a organização urbana atende a alguns critérios, os fluxos, o saneamento de água etc., ampliando a intervenção autoritária da medicina nos domínios da existência individual ou coletiva.

\section{Normalização e medicalização dos corpos}

Ewald (1993) traça uma importante descrição do que significa esse conceito de “norma" para Foucault. Trata-se, pois, de um elemento de ligação entre individualidades $\mathrm{e}$ as instituições. A norma, segundo Ewald (1993), corresponde a uma medida, ou seja, a uma produção de medida comum. É graças à norma que podemos definir a modernidade, uma vez que a sociedade normativa interfere no funcionamento das disciplinas "normalizando-as". Por essa razão, Foucault vai dizer que não devemos confundir "disciplinas" e "normas". As disciplinas são formas de adestramento do 
corpo, e a norma é quem especifica o sujeito, individualizando-o, tornando-o comparável.

\begin{abstract}
A norma permite abordar os desvios, indefinidamente, cada vez mais discretos, minuciosos, e faz que ao mesmo tempo esses desvios não enclausurem ninguém numa natureza, uma vez que eles, ao individualizarem, nunca são mais do que a expressão de uma relação, da relação indefinidamente reconduzida de uns com os outros (Ewald, 1993, p. 86).
\end{abstract}

De acordo com Foucault (2008c), nesse jogo das normalizações disciplinares, o que é fundante não é o "normal" ou o "anormal", mas sim a própria norma. É ela que vai dar o caráter primitivo de prescrição, estabelecendo a descrição do que é normal e do que não é, tornando-os presumíveis. Portanto, a norma é uma referência, sem se tornar modelo fixo. Ewald (1993) vai explicar ainda que a norma faz funcionar um sistema de comunicação que liga as individualidades, sem procurar uma origem ou um sujeito, "[...] manifesta antes a existência de um possível":

Do normal ao anormal, a linha é, pois, incerta. Não reenvia a nada na natureza. $\mathrm{O}$ anormal está na norma: o gigante tal como o anão, o idiota tal como o gênio. Mas isso não quer dizer que no espaço normativo não haja partilha possível, que não haja lugar para um processo de valorização. As práticas da norma não são relativistas. O normal opõese, de fato, ao anormal. Mas esta partilha é de um gênero especial: formula-se em termos de limiares e limites. [...] Compreende-se que ela nunca exprimirá uma lei da natureza; tão-só pode formular a pura relação do grupo consigo mesmo (Ewald, 1993, p. 87).

Foucault, no livro "Os anormais", inicia seus cursos sobre esse tema apresentando os três primeiros elementos que se formaram ao longo dos séculos XVII e XVIII, cujos investimentos de poder se debruçaram sob a forma de instituições, disciplinas e saberes constituindo e refinando os sujeitos a serem considerados dentro do campo das “anormalidades". Esses três elementos são: 1) o monstro humano - cujo contexto de referência é a lei, a noção jurídica. Esse elemento corresponde à figura que infringe tanto as leis da sociedade quanto as leis da natureza. 2) o indivíduo a ser corrigido Foucault (2010a) vai dizer que seu contexto é a própria família e que essa é uma figura específica dos séculos XVII e XVIII) a criança masturbadora - cujo contexto é mais estreito que a família: o quarto, a cama, o corpo. As três figuras 
estiveram bem demarcadas por características específicas e saberes determinados.

Foucault nesses cursos vai dizer que o monstro é uma exceção, um duplo de animal e espécie humana, que se torna um problema tanto para o saber médico quanto para o judiciário. Essa figura é importante porque ele representa a infração à lei, às leis da natureza desvelando suas irregularidades possíveis. Logo, o monstro torna-se modelo de todas as discrepâncias e vai levantar a questão "Descobrir qual o fundo de monstruosidade que existe por trás das pequenas anomalias, dos pequenos desvios, das pequenas irregularidades é o problema que vamos encontrar ao longo de todo o século XIX” (Foucault, 2010a, p. 48). No segundo caso, do indivíduo a ser corrigido, sua taxa de frequência é mais recorrente. Quem investe nesse sujeito é uma economia de poder exercida pela família e pelas instituições que lhe são próximas. Assim, afirma Foucault que a escola, a oficina, a rua, a igreja e outras vão compor uma malha por onde esse indivíduo passa e é capturado a fim de que sejam investidos nele técnicas de correção. Contudo, ressalta Foucault (2010a, p.50), esse indivíduo a ser corrigido é na verdade incorrigível, já que,
Se apresenta como sendo a corrigir na medida em que fracassaram todas as técnicas, todos os procedimentos, todos os investimentos familiares e corriqueiros de educação pelos quais se pode tentar corrigi-lo. [...] E, no entanto, paradoxalmente, o incorrigível, na medida em que é incorrigível, requer um certo número de correções específicas em torno de si de sobreintervenções em relação às técnicas familiares e corriqueiras de educação e correção, isto é, uma nova tecnologia de reeducação.

Desse modo, Foucault vai situar essa figura como sendo um dos ancestrais mais próximos do indivíduo anormal do século XIX, servindo como suporte para todas as instituições criadas para abrigar os anormais. Em relação ao terceiro exemplo, "o masturbador", precisamente a criança masturbadora (aparece no fim do século XVIII e início do XIX), vai encontrar um investimento de poder em forma de microcélulas recaindo sobre o indivíduo e seu corpo. Para Foucault (2010a) a diferença entre este e os outros elementos, é que este aparece como uma figura universal, pois carrega consigo um segredo, que é ao mesmo tempo um segredo universal, já que se trata de uma prática que todos conhecem, contudo, não revelada, fazendo desse segredo um segredo compartilhado. 
Ele vai nos dizer que a organização dos saberes e das técnicas antropológicas do século XIX fará desse segredo universal a raiz para quase todos os males, privilegiando as doenças ou males corporais, doenças nervosas e psíquicas. Ou seja, configura-se uma etiologia sexual que será suporte ou princípio de explicação para todos os males e doenças. Em resumo, Foucault nos diz com esses três exemplos que o anormal do século XIX é descendente dessas três figuras: o monstro, o incorrigível, o onanista. Apesar de suas especificidades, são figuras que se comunicam entre si.

Elas permanecem afastadas até o século XIX, por conta da separação entre os saberes e os sistemas de poder que as institui. Da feita que esses sistemas de poderes e de saberes também começam a se comunicar o entrelaçamento entre elas vai se tornando mais visível. Assim, o monstro situa-se nos regimes de saber e de poder político-judiciário, bem como na história natural, que busca distinguir as espécies, os gêneros e os reinos, como reitera Foucault (2010a). Já o incorrigível situa-se no saber que está sendo constituído ao longo do século XVIII, que é o saber das técnicas pedagógicas, das técnicas de educação coletiva, de formação de aptidões. E o masturbador é capturado por uma nascente biologia da sexualidade, que ganhará sua regularidade científica em meados de 1820 a 1830 (Foucault, 2010a). Na passagem do século XVIII para o XIX, Foucault (2010a) afirma que há uma mudança nos mecanismos de poder, com o advento de novas tecnologias científicas e industriais, bem como o surgimento de políticas de governo (governamentalidade) que engendram outras concepções de Estado (Estado Liberal). Nesse ínterim, algumas alianças entre determinados saberes acontecem, como foi o caso da psiquiatria com a justiça, da medicina com a psiquiatria e da psiquiatria e a higiene pública.

Foucault (2010a) assevera que é a psiquiatria o saber responsável por "criar", "fabricar" o sujeito "anormal". Ela inventaria esse sujeito a partir das sutis transformações que fariam a passagem do monstro ao anormal. Essa passagem se daria então do monstro (o bicho papão, o exagero) para as anomalias (a monstruosidade é dividida em pequenas anomalias). Vale lembrar ainda, que nessa passagem a psiquiatria não era um ramo especializado da medicina geral. E que inclusive para ganhar um lugar de visibilidade, a psiquiatria recorria a alguns princípios de estruturação e organização da medicina para explicar determinados acontecimentos (situações de saúde a nível mental). Contudo, um lugar de destaque só 
foi conseguido quando esta passou a "elaborar" discursos que explicariam determinadas situações que ninguém mais conseguia pensar. Um exemplo sobre essa troca de posições de saber e autoridades, encontramos na aliança do poder médico com o poder judiciário quando se direciona para o sujeito considerado criminoso e se pergunta por suas "condições de racionalidade", ou "ausência de interesse", tal como apontam os documentos estudados por Foucault (2010a).

A lei, para ser aplicada, exigia que se soubesse se esse sujeito a ser julgado era louco ou não. Mas ela não possuía condições de materializar e nem de averiguar essa situação. Assim, recorre à psiquiatria conferindo-lhe poder de fazer essa identificação. Então, o debate sobre esse sujeito perscruta se ao cometer um crime há ou não racionalidade, ou seja, "interesse", por parte do criminoso. Se sim, este é julgado de acordo com o código penal.

A questão do ilegal e a questão do anormal, ou ainda a do criminoso e a do patológico, passam, portanto a ficar ligadas, e isso não se dá a partir de uma nova ideologia própria, nem de um aparelho estatal, mas em função de uma tecnologia que caracteriza as novas regras da economia do poder de punir (Foucault, 2010a, p. 78).
Nasce assim o monstro moral que, pertencendo à categoria jurídica, é apanhado pela psiquiatria que vai decodificá-lo nas análises sobre as pequenas perversidades, maldades infantis, pequenos desvios, etc. E nesse afã para poder existir como uma instituição de saber ela precisa realizar duas codificações: 1) codificar a loucura como doença; tornar patológico os discursos, os erros, as ilusões da loucura e no trato das análises fazer a sintomatologia, a nosografia, prognóstico, fichas clínicas, observações. 2) codificar a loucura como perigo: implantar o discurso que a doença pode se tornar um perigo social, portanto, é preciso criar medidas de proteção social. Desse modo, a proteção começa a funcionar em nome do saber médico e a psiquiatria age como um saber sobre a doença mental importante para a regulação da higiene pública (Foucault, 2010a).

Outro ponto de ligação importante entre saberes da medicina para o alargamento de suas práticas na sociedade deu-se por meio da neurologia. Assim, epilepsia e os automatismos vão servir de suporte para todos os sintomas psiquiátricos. Foucault destaca ainda nesses cursos que a família vai se tornar um dos primeiros alvos de investimento dessa medicalização, sobretudo, no investimento feito sobre as crianças e 
adolescentes, a fim de controlar a sua masturbação. Interessante, diz ele, o discurso inicialmente sobre essas situações não é moralizante, mas de somatização e de patologização. Ele descreve uma série de situações que são realizadas pelos médicos e de discursos elaborados a fim de sustentar a masturbação ou o comportamento sexual como causa etiológica das mais diferentes doenças. Daí em diante com essas alianças e a elaboração desses novos discursos a psiquiatria se atribui como tarefa percorrer na direção de todas as desordens e instaura a "explosão sintomatológica" na sociedade pondo em evidência, enfim, a norma, tal como destaca Foucault (2010a, p. 138):

\footnotetext{
Organizando esse campo fenomenologicamente aberto, mas cientificamente modelado, a psiquiatria vai por em contato duas coisas. De um lado, ela vai introduzir efetivamente, em toda a superfície do campo que ela percorre, essa coisa que lhe era até então parcialmente alheia, a norma, entendida como regra de conduta, como lei informal, como princípio de conformidade; a norma a que se opõe a irregularidade, a desordem, a esquisitice, a excentricidade, o desnivelamento, a discrepância. É isso que ela introduz pela explosão do campo sintomatológico. Mas sua ancoragem na medicina orgânica ou funcional, por intermédio da neurologia, permite-lhe chamar também a ela a norma entendida
}

\author{
num outro sentido: a norma como \\ regularidade funcional, como princípio de \\ funcionamento adaptado e ajustado; o \\ "normal" a que se oporá o patológico, o \\ mórbido, o desorganizado, a disfunção \\ (Foucault, 2010a, p. 138-139).
}

Com esse pequeno resumo da genealogia esboçada por Foucault sobre os anormais, quisemos mostrar a emergência desses conceitos importantes para nós, como os de "norma", "normal", "anormalidade", "medicalização", e como foram $\mathrm{o}$ resultado de procedimentos diversos, historicamente constituídos, e que em nossa contemporaneidade se atualiza constituindo uma biopolítica medicalizada, formadora de subjetividades adentradas num jogo que se forma na busca da saúde e de performances ideais, capturadas cada vez mais por uma biopolítica empresarial tal como abordaremos no próximo tópico.

\section{Conclusões provisórias}

Vamos encontrar um interessante estudo com Ortega e Zorzanelli (2010) sobre a visibilidade do corpo pela sociedade, que se institui por meio das práticas e saberes médicos. Tomando como referência temporal os séculos descritos no tópico anterior, principalmente o século XVIII. Esses autores esboçam um breve 
resumo do surgimento da medicina na esfera da visibilidade, a partir do advento de novas tecnologias e artefatos, possibilitando o escrutínio do corpo e alavancando os saberes médicos. $\mathrm{O}$ desbravamento da viscerabilidade do nosso corpo foi uma condição imprescindível desde o século XVIII para o desenvolvimento das explorações médicas, que culminaram nos alcances da medicina na contemporaneidade.

Esses autores destacam que a visão ou uma racionalidade pautada na visibilidade possibilitou aos discursos científicos privilégios capazes de situá-los no centro dos jogos de verdade. No campo da medicina esse acontecimento ganhou uma dimensão extraordinária se estendendo a todos os ramos que lhe compõem. É claro que esse procedimento é herdeiro das práticas científicas das ciências naturais que sempre tiveram a "visão" como elemento crucial para a comprovação da verdade. As ciências biológicas começaram a imitar os métodos de dissecação, estratificação, organização e outros que compunham as "vantagens diagnósticas de ver".

Diante dessa configuração Ortega e Zorzanelli (2010, p.17) se propõem analisar o papel das tecnologias de visualização médica na construção social e cultural das doenças. Assim, declaram os autores: "Os métodos de visualização se baseiam na crença de que o objeto representado está diretamente acessado como ele realmente é.", fazendo uma explícita relação entre "ver" e "realidade", como se a realidade fosse algo a ser "descoberta" ou "desvelada", e a visão a maneira mais eloquente de realizar essa "inteligibilidade".

Essa passagem para o território da visão deu-se segundo esses autores quando a pesquisa médica, que durante anos baseava-se na dedução morfológica e na comparação com outros animais, tem no método da observação outro caminho a trilhar. Primeiro que, para isso, uma mudança de investimento sobre o corpo e sobre a vida se fizeram importantes. Cresce a preocupação com o prolongamento da vida, evitando-se as doenças. O que já havia sido apontado por Foucault em Vigiar e Punir (2008d) e História da Sexualidade I: vontade de saber (2007) quando a vida passa a ser objetivada por investimentos políticos. Contudo, apesar do alcance das máquinas ser maior do que os dos sentidos, ressaltam os autores que mesmo com o uso das novas tecnologias para quantificação/verificação do corpo, os médicos continuaram a usar das inferências para justificar evidências "médicas". Assim, "um olhar livre de interpretação é uma ficção que oculta a adaptação às 
condições visuais estabelecidas socialmente desde longa data" (Ortega \& Zorzanelli, 2010, p.38).

Essa observação é importante para pensarmos em como o fascínio pela visibilidade nos captura, a ponto de sustentar determinados discursos no campo da verdade oferecendo sem pestanejar a esses discursos credibilidade que vão ser sancionadas por sua vez, culturalmente. Em "O nascimento da clínica" encontramos com Foucault (2004b) uma arqueologia do olhar médico sobre a vida, precisamente sobre o corpo e suas alterações morfisiológicas e patológicas. O "olhar" seja ele entendido como um recurso de percepção visual, seja como uma produção de saber, foi fundante para a hegemonia da medicina no campo da cientificidade: "o olho torna-se o depositário e a fonte da clareza; tem o poder de trazer à luz uma verdade que ele só recebe à medida que lhe deu a luz" (Foucault, 2004b, p.10). Da descoberta do Raio-X a outros instrumentos para a visualização interior do corpo, a abrangência dessas práticas compõe uma "tecnologização do diagnóstico" que vai atingir o campo da doença mental (Ortega \& Zorzanelli, 2010). É por meio da neurologia, preferencialmente habituada ao registro imagético do corpo "fora de controle" que a medicina vai tentar lidar com os problemas causados pelas situações em que a descrição anatômica-fisiológica não consegue encontrar registros no cérebro.

\begin{abstract}
Esse campo tem um ponto de gatilho, sobretudo nas décadas de 1950 e 1960, quando os pesquisadores passaram a utilizar scans por tomografia computadorizada - que culminou nos anos 1970 no uso clínico dessas tecnologias. [...] A ressonância magnética funcional tornou possível acompanhar, praticamente em tempo real, a ativação cerebral, ou seja, para que áreas o sangue se desloca. O conceito de base para as tecnologias de imageamento cerebral desenvolvidas mais recentemente, como a ressonância magnética funcional e a tomografia por emissão de prósitrons, é que uma mudança no fluxo sanguíneo regional pode refletir a atividade neural e as áreas desenvolvidas em determinada função ou tarefa (Ortega $\&$ Zorzanelli, 2010, p. 50, grifo do autor).
\end{abstract}

Essas visibilidades na saúde formam um novo campo do cuidado de si e na gestão dos corpos disciplinados e na regulação da população. Para Ewald (1993), com a economia de poder voltando-se para o corpo coletivo, cria-se um novo dispositivo chamado "segurança", que vai marcar a passagem então da microfísica para o plano biopolítico, tendo no conceito de "risco" um homólogo do 
que era a "norma" para as disciplinas. Portanto,

O que é um risco? Na linguagem corrente, o termo é tomado como sinônimo de perigo, de acontecimento funesto que pode suceder a qualquer um; designa uma ameaça objectiva. Na segurança, o termo de risco não designa nem um acontecimento nem mesmo um tipo de acontecimento da realidade - os acontecimentos "funestos" - mas um mundo de tratamento específico de certos acontecimentos que podem suceder a um grupo de indivíduos, ou mais exatamente a valores ou capitais possuídos ou representados por uma coletividade de indivíduos, ou seja, por uma população. Em si mesmo, nada é um risco, não existe risco na realidade. Inversamente, tudo pode constituir um risco, tudo depende da maneira como se analisa o perigo, como se considera o acontecimento (Ewald, 1993, p. 88-89).

E sobre essa noção de risco uma racionalidade é conjecturada formalizando o cálculo das probabilidades, em que diversos elementos começam a entrar num jogo de lógica estatística a fim de se calcular os aparentes "riscos". Para Ewald (1993, p. 90) tem-se um cálculo das regularidades em que cada evento ocorre e um cálculo das possibilidades de novas ocorrências. Esse duplo processo transforma os eventos em "pura factualidade": "Reduz a uma pura acumulação de fatos, de dados que se amontoam desesperadamente. Porque, na medida em que a rede habitual dos significados foi suspensa, todos os fatos, até os que a instantes podiam parecer os mais insignificantes, devem ser notados, sem hierarquia e nem privilégio".

Nessa processualidade das multiplicidades o "número" torna-se um elemento importante, porque ocupa o lugar do sentido, ou seja, ele "faz sentido por si mesmo. A noção de massa (de população, de coletividade) toma o lugar da natureza ou de essência" (Ewald, 1993, p. 91). Assim, de acordo com os autores, os fatos se organizam por categorias, de acordo com alguns nomes: "nascimento, morte, acidente, suicídio, avaliação", preocupando-se apenas com os efeitos dos riscos, sobrepujando as causas nessa racionalidade das probabilidades. Foucault (2008c) vem falar das governamentalidades liberais que criam essa racionalidade, ampliando os campos de exercício das tecnologias de poder. Para ele, nos dispositivos de segurança a liberdade é elemento fundamental dessas tecnologias de poder das quais temos falado ao longo do texto. Primeiro que a ideia ou como queiram a ideologia da liberdade, foi quem deu condições de desenvolvimento dessas formas modernas capitalistas de economia. Assim, a 
liberdade, nos afirma Foucault (2008c, p. 63-64) é ao mesmo tempo uma ideologia e técnica de governo:

\begin{abstract}
Um dispositivo de segurança só poderá funcionar bem, [...] justamente se lhe for dado certa coisa que é a liberdade, no sentido moderno [que essa palavra] adquire no século XVIII: não mais as franquias e os privilégios vinculados a uma pessoa, mas a possibilidade de movimento, de deslocamento, processo de circulação tanto de pessoas como das coisas. [...] um poder que se pensa como regulação que só pode se efetuar através de e apoiando-se na liberdade de cada um.
\end{abstract}

Desse modo, esse conceito de liberdade para Foucault extrapola a concepção ideológica porque ela atua fundamentalmente como uma tecnologia de poder, numa gestão governamental cujo saber predominante é a economia política. Essa economia política a partir do século XVIII vai pensar e colocar em funcionamento os dispositivos de segurança que atuem no conjunto da população, dessa forma, um modo de lidar com as multiplicidades: crescimento e organização das cidades, circulação das pessoas, mercadorias, natalidade, mortalidades, fluxos, doenças etc. (Foucault, 2008c). Essas multiplicidades vão ser geridas por uma racionalização do acaso e das probabilidades, como forma de intervir na população, penetrá-la:

\begin{abstract}
A população é, portanto, tudo o que vai se estender do arraigamento biológico pela espécie à superfície de contato oferecida pelo público. Da espécie ao público: temos aí todo um campo de novas realidades, novas realidade no sentido de que são, para os mecanismos de poder, os elementos pertinentes, o espaço pertinente no interior do qual e a propósito do qual se deve agir (Foucault, 2008c, p. 99).
\end{abstract}

A medicalização encontra nessa racionalidade probabilística um ponto de encontro para sua ancoragem: “Governar o futuro traz a lógica da gestão do risco para o presente em deslizamento com o perigo a evitar para defender e assegurar a sociedade daquilo que teme e, portanto, visa a se prevenir como tentativa de controle biologizante e político" (Galindo, Lemos \& Rodrigues, 2014, p. 258). Essa governamentalidade cria outros espaços/tempos de experiências subjetivas cada vez mais marcadas por uma sociabilidade medicalizada, onde a preocupação com o controle e regulação da vida está pautada em um dos aspectos da lógica médica. Assim, se a noção de risco impõe à sociedade um "medo" do acaso, do futuro, a medicalização é aceita ou naturalizada em diversos aspectos, porque entra nessa lógica da segurança, 
convencendo as pessoas de que o melhor é fazer um investimento em si mesmas, em sua saúde, aderindo às diversas formas de "seguros". Biopolítica empresarial e governamentalidade neoliberal, portanto, gerindo os eventos da vida e transformando-os em mercadorias a serem privatizados, tal como sugerem as autoras:

A privatização da vida como biocapital faz parte de toda uma economia política que entra em cena por meio do cálculo da virtualidade, baseado em amostras e em indicadores genéticos utilizados como um mapa da gestão da vida, do fazer viver biopolítico, juntamente com a ampliação de habilidades futuras e produtivas da disciplina usada por antecipação, em termos de controle dos corpos no tempo e no espaço (Galindo, Lemos \& Rodrigues, 2014, p. 256).

Nesse mesmo trabalho, Galindo, Lemos e Rodrigues (2014) discorrem sobre o mercado privado que se confeccionou em torno da coleta das células-tronco do cordão umbilical. O material coletado é transformado em um capital de risco biológico, pondo em circulação discursos sobre a necessidade futura de crianças virem a ter algum problema de saúde. Criam-se argumentos em torno da probabilidade do aparecimento de doenças que nem se quer existem e a promessa da participação do cliente nesse controle medicalizante, mantido pelo pagamento regular de taxas para sua manutenção. Ressaltam ainda as autoras que a preocupação com o desenvolvimento das crianças, a classificação desse desenvolvimento em ciclos, gera um capital a regular e administrar, operando ao mesmo tempo investimentos numa "segurança pela prevenção" e numa “docilização pela educação". Ou seja, temos aí, as duas tecnologias de poder, disciplinar e biopolítica, operando simultaneamente na gestão da vida.

São duas formas de poder que capturam a vida por meio de discursos e saberes que põem em funcionamento uma rede entrecruzada de forças, onde transversalmente lhe tangenciam práticas liberais que realizam um controle social utilitarista tanto no plano coletivo quanto no microfísico, individual. De acordo Lemos, Cruz e Souza (2014, p. 09):

[...] é relevante problematizar a gestão utilitarista dos corpos individuais e em grupo no presente, materializada de forma cada vez mais linear e determinista, em termos de medicalização da educação. Estes procedimentos reducionistas da biomedicina são intensificados na visão da escola e dos processos de ensinoaprendizagem, limitadas às neurociências, aos aspectos neurobiológicos e comportamentais apenas. 
A objetivação da educação por práticas medicalizantes é um assunto que vem sido trabalhado desde a década de 1980 (Collares \& Moysés, 1982, 1992) e se expõe em pesquisas na atualidade (Galindo et al, 2014, Facci \& Souza, 2014, Moyses \& Collares, 2014, Souza, 2014, 2009, 2005, 2000), por conta da enxurrada de procedimentos, tecnologias, fármacos, discursos, que operam nessa racionalidade biomedicalizante, tendo na esfera da educação, principalmente a educação básica, seu maior expoente.

A medicalização se generaliza nesses domínios de poder e criam performances que são geridas por essas formas de controle pautadas por discursos de saúde, engendrados em enunciações proferidas em nome da paz e da segurança. Contudo, estes são pautados pela lógica do mercado uma vez que são ideias vendidas na educação, no trabalho e na saúde. Para Deleuze (2008, p. 223) essa "sociedade de controle" em que vivemos, produz um homem "ondulatório, funcionando em órbita, num feixe contínuo", contudo, endividado, porque no capitalismo de nossa atualidade, esse se volta para o produto, para sua venda, transformando tudo em produtos venais por meio do marketing.

Essa noção de marketing opera como ferramenta de controle social, que age desde a esfera individual (marketing de si mesmo, empresário de si) quanto no coletivo (conquista de novos mercados a todo tempo). No que tange a educação, ele cita "as formas de controle contínuo, a avaliação contínua, e a ação da formação permanente sobre a escola, o abandono correspondente de qualquer pesquisa na Universidade, a introdução da 'empresa' em todos os níveis de escolaridade" (Deleuze, 2008, p. 225). A esse respeito ressaltam Lemos, Cruz e Souza (2014, p. 14):

O marketing escolar e empresarial
modulará cada vez mais detalhadamente a
vida e os pequenos atos cotidianos como
investimentos e marketing. Tudo pode se
tornar marca e signo de sucesso pessoal e
relacional e nome de um mercado
crescente, que comercializa até mesmo os
sentimentos, as amizades, a docência, a
educação familiar e religiosa, a
performance física e a cultural.

Uma das consequências advindas desse tipo de racionalidade da vida, guiadas pela lógica mercadológica e medicalizante, segundo estes autores é o silenciamento das diferenças. Isto se dá pelo discurso de uma "educação para a paz”, que está se materializando por meio de "[...] medidas médico-psicológicas e as programações de risco de caráter 
cognitivo-comportamentais ou ainda, as teorias das relações humanas, os psicotrópicos, os exercícios físicos e as aulas de arte e lazer [...]" (Lemos, Cruz \& Souza, 2014, p. 14).

Esses acontecimentos despertam interesse e nos guiam na construção desse trabalho doutoral e nos convida a pensar que por mais que não haja uma relação de causalidade entre esses elementos e as práticas produzidas nos documentos que compõem o currículo de formação em psicologia, contudo, na malha que se forma entre esses acontecimentos, as práticas em funcionamento operadas por esse currículo não são neutras, agenciam forças políticas, oriundas da produção e disputa de saberes que intencionam seu locus nesse currículo. Desse modo, como assinala Veyne (2008, p. 248), é preciso estudar as práticas não como uma "instância misteriosa, um subsolo da história, um motor oculto [...] Existem regras estritas que sustentam as práticas [...] que é uma certa política" Logo, por meio dessa arqueogenealogia que se pretende desenvolver nessa pesquisa, busca-se pela raridade desse acontecimento por meio da interpelação das práticas que o produzem, ou seja, dando visibilidade as objetivações de práticas determinadas historicamente.

Os operados conceituais que foram apresentados nessa seção nos ajudaram com elementos aos quais estamos utilizando como marco inicial para problematizar as práticas medicalizantes que por meio de desníveis discursivos compõem o currículo de psicologia e que atuam como filtro silenciador das diferenças. A literatura levantada sobre a formação em psicologia no Brasil, por meio das diferentes perspectivas as quais foram trabalhadas, nos indicaram as condições históricas pelas quais teríamos que nos debruçar a fim de que fosse possível transitar pelas histórias contadas sobre o campo de tensões formadas por diferentes grupos, sob o registro de diferentes posicionamentos teóricos, almejando adentrar nas lutas empreendidas para compor um projeto de sociedade.

\section{Referências}

Aquino, J. G. (2013). A difusão do pensamento de Michel Foucault na educação brasileira: um itinerário bibliográfico. Revista Brasileira de Educação. Rio de Janeiro, 18(53), abr.-jun. Recuperado de https://www.scielo.br/scielo.php?pid= S1413-

24782013000200004\&script $=$ sci abstr act\&tlng=pt\#: :text=0\%20presente $\%$ 20artigo\%20tem\%20o,per\%C3\%ADo do\%20entre\%201990\%20e\%202012.

Boarini, M. L. (2007). A formação do psicólogo. Psicologia em Estudo, Maringá, 12(2), 443-444, maio/ago. Recuperado de 
https://www.scielo.br/scielo.php?script =sci_arttext\&pid=S1413-

$\underline{73722007000200027 \& n r m=i s o \& t \operatorname{lng}=}$ $\mathrm{pt}$

Camargo Jr. K. R. de. (2007). As armadilhas da "concepção positiva de saúde". Physis: Revista de Saúde Coletiva, Rio de Janeiro, 1(76), 63-76. Recuperado de https://www.scielo.br/scielo.php?pid= S0103-

73312007000100005\&script=sci abstr act\&tlng $=\mathrm{pt}$

Candiotto, C. (2007). Verdade e diferença no pensamento de Michel Foucault. Kriterion. Belo Horizonte, 115, 203217, jun. Recuperado de https://www.scielo.br/scielo.php?script $=$ sci abstract\&pid=S0100-

512X2007000100012\&lng $=$ en\&nrm=i so\&tlng=pt\#: :text=Kriterion $\% 20 \% 5$

Bonline\%5D.,2007\%2C\%20vol.\&text $=0 \% 20$ presente $\% 20$ artigo \%20versar $\% \mathrm{C} 3 \% \mathrm{~A} 1 \% 20$ sobre,origin\%C3\%A1ri a\%20e\%20universalista\%20de\%20ver dade.

Castro, E. (2009). Vocabulário de Foucault. Um percurso pelos seus temas, conceitos e autores. Belo Horizonte: Autêntica.

Collares, C. L., Moysés, M. A. A. (1982). Desnutrição e fracasso escolar: uma relação tão simples? Revista $d a$ ANDES. Brasília, 5, 56-62.

Collares, C. L.; Moyses, M. A. A. (1994). A Transformação do Espaço Pedagógico em Espaço Clínico (A Patologização da Educação). São Paulo, FDE, 25-31. Série Ideias (23).

Collares, C. L.; Moyses, M. A. A. (1992). A história não contada dos distúrbios de aprendizagem. Caderno Cedes, São Paulo, (28), 31-48.
Costa, S. de S. G. (2009). Governamentalidade neoliberal, Teoria do Capital Humano e Empreendedorismo. Revista Educação e Realidade, Porto Alegre, 2(34), 171186, mai/ago. Recuperado de https://seer.ufrgs.br/educacaoerealidad e/article/view/8299

Deleuze, G. (2008). Conversações. São Paulo: Editora 34.

Ewald, F. (1993). Foucault: a norma e o direito. Lisboa: Vega.

Farhi Neto, L. (2010). Biopolíticas: as formulações de Foucault. Florianópolis: Cidade Futura.

Foucault, M. (2000c). O que é a crítica. Trad.: Antônio C. Galdino. Cadernos da Faculdade de Filosofia e Ciências Humanas. UNESP, Marília, 9(1).

Foucault, M. (2004a). A ordem do discurso. Aula inaugural no Collège de France, pronunciada em 2 de dezembro de 1970. São Paulo: Loyola.

Foucault, M. (2004b). O nascimento da clínica. 6a.ed. Rio de Janeiro: Forense Universitária.

Foucault, M. (2004c). O uso dos prazeres e as técnicas de si. In: Mota, M. B. (Org.). Ética, sexualidade e política. Rio de Janeiro: Forense Universitária (Ditos e Escritos, Vol. V).

Foucault, M. (2005a). História da sexualidade I: A vontade de saber. 17. ed. Rio de Janeiro: Graal.

Foucault, M. (2005b). Em defesa da Sociedade: curso no Collège de France (1975-1976). 25. ed. São Paulo: Martins Fontes. 
Foucault, M. (2006). Diálogo sobre o poder. In: Mota, M. B. da (Org.). Estratégia, poder, saber. 2. ed. Rio de Janeiro: Forense Universitária, (Ditos e Escritos, Vol. IV).

Foucault, M. (2008a). O nascimento da medicina social. In: Microfísica do poder. 25. ed. Rio de Janeiro: Graal.

Foucault, M. (2008b). A polícia da saúde no século XVIII. In: Microfísica do poder. 25. ed. Rio de Janeiro: Graal.

Foucault, M. (2008c). Segurança, Território e População. São Paulo: Martins Fontes.

Foucault, M. (2008d). Vigiar e punir: nascimento da prisão. 35. ed. Petrópolis, RJ: Vozes.

Foucault, M. (2008g). Sobre a história da sexualidade. In: Microfísica do Poder. $25^{\mathrm{a}}$. ed. Rio de Janeiro: Edições Graal.

Foucault, M. (2008h). Nascimento da biopolítica. São Paulo: Martins Fontes.

Foucault, M. (2008i). A casa dos loucos. In.: Microfísica do Poder. $25^{\mathrm{a}}$. ed. Rio de Janeiro: Edições Graal.

Foucault, M. (2010a). Os anormais: Curso no Collège de France (1974-1975). São Paulo: Editora WMF Martins Fontes.

Foucault, M. (2010b). O sujeito e o poder. In: Rabinow, P. \& Dreyfus, H. Michel Foucault: uma trajetória filosófica para além do estruturalismo e da hermenêutica. Rio de Janeiro: Forense Universitária.

Foucault, M. (2010c). A hermenêutica do sujeito: curso dado no Collège de France (1981-1982). $3^{a}$ ed. São Paulo: Editora WMF Martins Fontes.
Foucault, M. (2011a). O estilo da história [1984]. In.: Mota, M. B. da. (Org.). Arte, epistemologia, Filosofia e História da Medicina. Coleção: Rio de Janeiro: Forense Universitária. (Ditos e Escritos VII).

Foucault, M. (2011b). Crise da Medicina ou crise da Antimedicina. In.: Mota, M. B. da. (Org.). Arte, epistemologia, Filosofia e História da Medicina. Coleção: Rio de Janeiro: Forense Universitária. (Ditos e Escritos VII).

Foucault, M. (2011c). A incorporação do hospital na tecnologia moderna. In.: Mota, M. B. da. (Org.). Arte, epistemologia, Filosofia e História da Medicina. Coleção: Rio de Janeiro: Forense Universitária. (Ditos e Escritos VII).

Foucault, M. (2011d). Bio-história e biopolítica. In.: Mota, M. B. da. (Org.). Arte, epistemologia, Filosofia e História da Medicina. Coleção: Rio de Janeiro: Forense Universitária. (Ditos e Escritos VII).

Foucault, M. (2011e). O que são as luzes? In.: Mota, M. B. da. (Org.). Arte, epistemologia, Filosofia e História da Medicina. Coleção: Rio de Janeiro: Forense Universitária. (Ditos e Escritos VII).

Foucault, M. (2013). A verdade $e$ as formas jurídicas. Rio de Janeiro: Nau.

Gadelha, S. (2012). (Bio)política, democracia, pluralismo e educação: dilemas que demandam uma politização outra. In.: Pagni, P. A., Bueno, S. F., Germano, R. P. (Orgs.). Biopolítica, arte de viver e educação. Marília: Oficina Universitária; São Paulo: Cultura Acadêmica. 
Galindo, D.; Lemos, F. C. S.; Rodrigues, R. V. (2014). A vida como biocapital - futuros biológicos, uma aposta dos bancos privados de células-tronco de cordão umbilical no Brasil. Athenea Digital, Barcelona: Espanha, 2(14), 255-274, julho.

Guarido, R. (2007). A medicalização do sofrimento psíquico: considerações sobre o discurso psiquiátrico e seus efeitos na Educação. Revista Educação e Pesquisa, São Paulo, 33(1), 151-161, jan./abr.

Lemos, F. C. S. (2014). A medicalização da educação e da resistência no presente: disciplina, biopolítica e segurança. Revista Quadrimestral da Associação Brasileira de Psicologia Escolar e Educacional, São Paulo, 18(3), set./dez.

Lemos, F. C. S.; Cruz, F. F.; Souza, G. S. (2014). Medicalização da produção da diferença e racismo em algumas práticas educativas pacificadoras. Revista Profissão Docente, Uberaba, 14(30), 07-20, jan./jun.

Martins, A. (2004). Biopolítica: o poder médico e a autonomia do paciente em uma nova concepção de saúde. Revista Interface - Comunicação, Saúde, Educação. 8(14), 21-32, fev.

Monteiro, H. R. (2006). Medicalização da vida escolar. Dissertação (Mestrado). Programa de Pós-Graduação em Educação. Universidade Federal do Estado do Rio de Janeiro.

Ortega, F.; Zorzanelli, R. (2010). Corpo em evidência: a ciência $e \quad a$ redefinição do humano. Rio de Janeiro: Civilização Brasileira. (Coleção Contemporânea).
Peters, M. (2002). Governamentalidade neoliberal e educação. In.: Silva, T, T. da. (Org.); Sujeito da educação: estudos foucaultianos. $5^{\mathrm{a}}$. ed. Petropólis, RJ: Vozes.

Popkewitz, T. S. (2002). História do Currículo, regulação social e poder. In. Silva, T. T. da. (Org.). O sujeito da educação: estudos foucualtianos. 5a. ed. Petrópolis, RJ: Vozes.

Rabinow, P.; Rose, N. (2006). O conceito de biopoder hoje. Revista de Ciências Sociais. Política \& Trabalho, João Pessoa, n. 24, abril, 27-57.

Veiga-Neto, A. (2009). O currículo e seus três adversários: os funcionários da verdade, os técnicos do desejo, o fascismo. In.: Rago, M. Veiga-Neto, A. (Org.). Para uma vida não-fascista. Belo Horizonte: Autêntica. (Coleção Estudos Foucaultianos).

Veyne, P. (1983). O inventário das diferenças - história e sociologia. São Paulo: Editora Brasiliense.

Veyne, P. (2008). Foucault revoluciona a história. In: Como se escreve a história. 4a. ed. Brasília: UNB.

Flavia Cristina Silveira Lemos é professora associada II em psicologia social/UFPA, bolsista de produtividade em pesquisa CNPQ PQ2. Psicóloga-UNESP, mestre em Psicologia Social-UNESP e doutora em História Cultural-UNESP.

E-mail: flaviacslemos@gmail.com ORCID: http://orcid.org/0000-0002-6601$\underline{0653}$

Geise do Socorro Lima Gomes é psicóloga pela UFPA, mestre em Psicologia (UFPA) e também doutora em Educação (UFPA).

E-mail: geisepsi@gmail.com 
ORCID: $\quad$ https://orcid.org/0000-00019059-8568

Paulo de Tarso Ribeiro de Oliveira é psicólogo ( UFPA), mestre e doutor em Saúde do trabalhador na ENSP-FIOCRUZ. É também coordenador do Programa de Pós-graduação em Psicologia da UFPA e professor associado II de Psicologia Social do trabalho - UFPA.

E-mail: pttarso@gmail.com

ORCID: https://orcid.org/0000-00021969-380X

Dolores Cristina Gomes Galindo é psicóloga (UFPE), mestre e doutora em Psicologia Social - PUC-SP e professora associada II de Psicologia Social da UFMT. É também professora no Programa de Pós-graduação de Estudos da Cultura Contemporânea-UFMT.

\section{E-mail:}

dolorescristinasilveiralemos@gmail.com ORCID: http:orcid.org0000-0003-2071-

$\underline{3967}$

Enviado em: 02/06/19- Aceito em: 07/07/20 